\title{
Urinary excretion of 5-L-oxoproline (pyroglutamic acid) during early life in term and preterm infants
}

\author{
Alan A Jackson, C Persaud, M Hall, S Smith, N Evans, N Rutter
}

Institute of Human

Nutrition,

University of

Southampton,

Southampton

SO16 7PX

A A Jackson

C Persaud

Neonatal Medical Unit,

Princess Anne

Hospital,

Southampton

M Hall

S Smith

Department of Child

Health,

Queen's Medical

Centre,

Nottingham

N Evans

N Rutter

\section{Correspondence to:} Professor A A Jackson.

Accepted 29 January 1997

\begin{abstract}
Urinary 5-L-oxoproline was measured in term and preterm infants from shortly after birth until 6 weeks of postnatal age to determine their ability to synthesise glycine. In term infants the excretion was five to 10 times that seen in normal adults, increasing from $105 \mu \mathrm{mol} / \mathrm{mmol}$ creatinine in the first 72 hours after birth to 170 $\mu \mathrm{mol} / \mathrm{mmol}$ creatinine at 6 weeks of age. There was a significant inverse linear correlation between the excretion of 5-Loxoproline and length of gestation or birthweight. By 6 weeks of age there was no longer a significant difference in 5-Loxoproline between term and preterm infants. There was no difference in the excretion of 5-L-oxoproline between boys and girls, or between infants fed on human milk or an artificial formula.
\end{abstract}

If, in part, variability in the excretion of 5-L-oxoproline is determined by the extent to which the endogenous formation of glycine is adequate, then glycine formation may be marginal during early life, more so in preterm than in term infants, providing additional evidence that glycine is a conditionally essential amino acid in the neonate.

(Arch Dis Child 1997;76:F152-F157)

Keywords: glycine; $\gamma$-glutamyl cycle; protein synthesis; conditionally essential amino acids

The ability of neonates to synthesise adequate amounts of non-essential amino acids is determined by the maturation of the appropriate

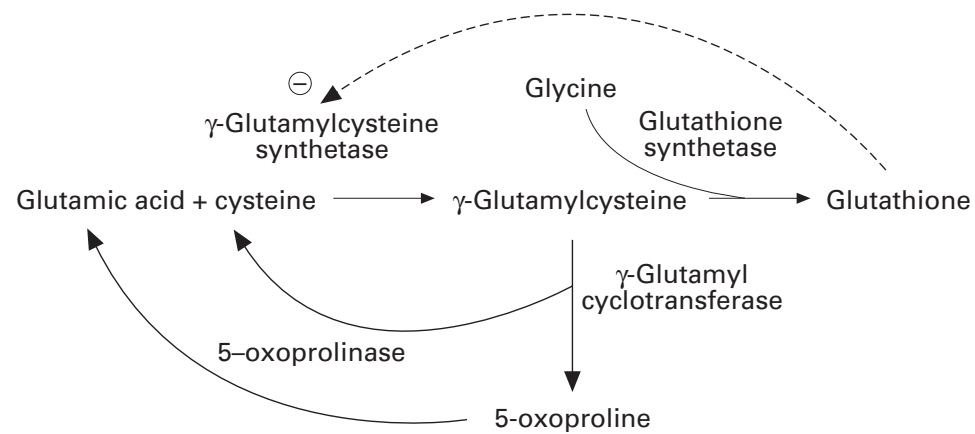

Figure 1 Glutathione, $\gamma$-glutamylcysteinlglycine is synthesised in two stages catalysed by glutamate-cysteine ligase ( $\gamma$-glutamylcysteine synthetase) (EC 6.3.2.2), and glutathione synthase (EC 6.3.2.3). Glutathione inhibits feedback on $\gamma$-glutamylcysteinlglycine synthase, so that in the congenital absence of glutathione glutamate excess

$\gamma$-glutamylcysteinlglycine is cleaved by, $\gamma$-glutamyl cyclotransferase (EC 2.3.2.4) to give 5-L-oxoproline, which can be converted to glutamic acid by 5-L-oxoprolinase. Increased urinary 5-L-oxoproline is also produced when the availability of glycine, the substrate for glutathione synthetase, is limited. enzyme systems and the availability of cofactors. One amino acid for which endogenous formation may be marginal is glycine and we have shown that in preterm infants glycine may be conditionally essential. ${ }^{2}$ Glycine may be the first limiting nutrient for growth in infants on low protein diets as weight gain is improved by dietary supplementation. ${ }^{3}$ There is no direct way of measuring the metabolic requirement for glycine, nor the ability of the body to satisfy that need. However, we have used the urinary excretion of 5-L-oxoproline as a non-invasive marker for glycine status. ${ }^{4}$

Although large amounts of 5-L-oxoproline are normally produced as an intermediary in the formation of glutathione in the $\gamma$-glutamyl cycle $^{6}$ (fig 1), urinary excretion is very low. Glutathione exerts feedback control on its own formation, to decrease the rate of synthesis of $\gamma$-glutamyl cysteine. With a congenital absence of glutathione synthetase (EC 6.3.2.3) glutathione concentrations are low and the rate of formation of $\gamma$-glutamylcysteine is increased, but it cannot be further metabolised to glutathione. Under these circumstances $\gamma$-glutamylcysteine follows an alternative metabolic fate, being hydrolysed to cysteine and 5-L-oxoproline, through internal cycling of the glutamic acid. Excessive production of 5-L-oxoproline exceeds the capacity of 5-L-oxoprolinase, resulting in accumulation of 5-L-oxoproline in plasma, renal overflow, and increased excretion in urine. A limitation in the availability of glycine, the other substrate for glutathione synthase, also leads to an increase in the excretion of 5-L-oxoproline in urine. ${ }^{4}$

During growth, the demands for glycine are high, both absolutely and relative to other amino acids. ${ }^{7}$ The accumulation of glycine as protein in the body of the developed fetus is twice to 10 times that for any other amino acid on a molar basis ${ }^{8}$ and glycine is one of two amino acids made in large amounts by the placenta for the fetus. ${ }^{9}$ The neonate conserves glycine by reducing its degradation, ${ }^{12}$ and limiting its use for bile salt production, ${ }^{10}{ }^{11}$ or conjugation with xenobiotics such as benzoic acid. ${ }^{12}{ }^{13}$ In infants gaining weight rapidly during recovery from severe malnutrition, increased excretion of 5-L-oxoproline excretion may be reduced if the diet is supplemented with additional glycine. ${ }^{14}$

We found very high rates of 5-L-oxoproline excretion in a small number of preterm infants in a preliminary study (Bulpitt and Jackson, unpublished observations). The objective of the present study was to characterise the excre- 
tion of 5-L-oxoproline in the urine of normal term and preterm infants.

\section{Methods}

The studies were carried out in infants born in Nottingham and Southampton and were approved by the relevant ethical committees in each site. Many of the data were collected as a part of larger metabolic studies.

Term infants were identified as having completed 37 weeks of gestation based on the date of the mother's last menstrual period and examination by the attending obstetrician. None of the infants in the study had mothers with any major illness, and none had a congenital abnormality nor any other serious ongoing illness. Timed collections of urine in infancy are difficult. We have found that when the excretion of 5-L-oxoproline is expressed as a daily rate, in relation to body weight, or as a ratio to urinary creatinine excretion, in adults, similar information is obtained. ${ }^{5}$ In a preliminary study the excretion of 5-L-oxoproline was measured in the urine of eight infants born around 33 weeks of gestation (95\% CI 31-34 weeks) who were part of a metabolic balance study in Southampton in which urine was collected for a period of 72 hours. The birthweight of the infants was $1.87 \mathrm{~kg}$ (95\% CI $1.37-2.37$ $\mathrm{kg}$ ) and at the time of study the infants were 6 weeks of age. The total daily excretion of 5-Loxoproline and excretion expressed as $\mu \mathrm{mol} /$ mmol creatinine were measured and compared with the excretion in spot, or casual, samples of urine in 13 infants of similar gestation (mean 32.3 weeks, $95 \%$ CI 31.5-33.0 weeks), birthweight (mean $1.78 \mathrm{~kg}, 95 \%$ CI $1.52-2.04 \mathrm{~kg}$ ) and age. The daily excretion of 5-L-oxoproline was $21 \mu \mathrm{mol}(95 \%$ CI $10-32 \mu \mathrm{mol} /$ day). The concentration of 5-L-oxoproline in the timed samples collected over 72 hours $(205 \mu \mathrm{mol} /$ mmol creatinine, $95 \%$ CI $144-267 \mu \mathrm{mol} / \mathrm{mmol}$ creatinine) was not different from the concentration of 5-L-oxoproline in spot samples of urine $(220 \mu \mathrm{mol} / \mathrm{mmol}$ creatinine, $95 \%$ CI 124-316 $\mu \mathrm{mol} / \mathrm{mmol}$ creatinine). Therefore, the results have been expressed as a ratio to the excretion of creatinine in the same urine.

In Nottingham urine was collected into sterile urine bags from 30 infants, 10 term and 20 preterm. In the term infants urine was collected on days 2,8 , and at the end of weeks 3 and 6 . In preterm infants samples were collected on days 2,8 , and at the end of weeks $2,3,4$ and 6 . The earlier samples were collected while the infant was still in hospital, with the later samples being collected in the infant's home. The urine was stored frozen until analysis. The birthweight of each child was abstracted from the hospital notes and the feeding history was recorded as either solely breastfed, fed with an infant formula (SMA, Wyeth Laboratories, England), or a mixture of the two.

In Southampton urine was collected from 63 infants, 17 term and 46 preterm infants. In both sets of infants the first urine was collected within 48 hours of birth and then at weekly intervals. Early samples of urine were collected in the hospital. The birthweight of each child was abstracted from the hospital notes and the feeding history was recorded as either human breast milk (expressed or banked) or an infant formula (Preaptamil, Milupa, England). After collection the urine was preserved in $6 \mathrm{~N} \mathrm{HCl}$, $250 \mu \mathrm{l}$, and stored frozen at $-4^{\circ} \mathrm{C}$. The concentration of 5-L-oxoproline and creatinine in urine were measured.

\section{BIOCHEMICAL ANALYSES}

Urinary 5-L-oxoproline was measured using a modification of the method of van der Werf et $a l .{ }^{15}$ This approach ensures that 5-Loxoproline is measured without any contamination from 5-D-oxoproline which may be present, derived from the diet, or produced by the colonic microflora. 5-Oxoproline was isolated by short column ion-exchange chromatography, free from glutamate, and other amino acids. The 5-L-oxoproline in the eluate was hydrolysed in hot acid to glutamic acid ${ }^{16}$ and the resulting L-glutamic acid measured enzymatically with glutamate dehydrogenase (EC 1.4.1.2.)..$^{517}$ Creatinine in the urine was measured using the alkaline picrate method of Jaffe, as described by Bonsnes and Taussky, ${ }^{18}$ after pretreatment of the urine with Lloyd's reagent to remove interfering chromogens.

\section{STATISTICAL ANALYSIS}

For analysis, the infants were divided into four groups according to gestational age: below 28 weeks, 29 to 32 weeks, 33 to 36 weeks and over 37 weeks. Normality of distribution was tested using the Kolmogorov-Smirnov goodness of fit test. Groups were compared using analysis of variance with post-hoc Scheffe's multiple range test, and where appropriate, a correction was made for confounding variables. Differences between groups were sought with the $t$-test for paired and unpaired data. Associations between variables were sought using linear regression analysis. Data were analysed using SPSS 6.0 for Windows. A P value of $<0.05$ on a two tailed test was taken as indicating a significant difference. Results are expressed as the mean and $95 \%$ confidence intervals $(95 \%$ CI).

\section{Results}

Samples of urine were collected from 93 infants altogether, although complete information on the gender or method of feeding was not available on each infant. There were similar proportions of girls and boys in the samples from Nottingham and Southampton. About one third of the infants in each group were term deliveries. In the Nottingham sample two thirds of the infants were given human milk, whereas in Southampton two thirds received an infant formula.

The infants were divided into four groups according to gestational age (table 1), with similar numbers in each group. The average weight for each group is shown in table 1. For the entire group, 12 infants were small for gestational age (birthweight below the third centile for weight) with similar numbers in each birth weight category $\left(\chi^{2}, \mathrm{P}=0.88\right)$. Table 1 shows the excretion of 5 -L-oxoproline, $\mu \mathrm{mol} /$ 
Table 1 Excretion of 5-L-oxoproline measured in urine of term and preterm infants within first 72 hours of birth and at intervals until 6 weeks of age

\begin{tabular}{|c|c|c|c|c|c|}
\hline & \multicolumn{4}{|l|}{ Time of birth } & \multirow[b]{2}{*}{ Pvalue } \\
\hline & $<28$ weeks $(n=27)$ & 29-32 weeks $(n=22)$ & $33-36$ weeks $(n=27)$ & $>37$ weeks $(n=17)$ & \\
\hline Gestation (weeks) & $26.4^{\star}+\ddagger(25.8-26.9)$ & $30.4^{\star}+(29.3-30.8)$ & $34.5^{\star}(34.0-34.9)$ & $39.8(39.6-40.0)$ & 0.0000 \\
\hline Birth weight (kg) & $1.01^{\star}+\ddagger(0.86-1.16)$ & $1.53^{\star}+(1.41-1.66)$ & $2.06^{\star}(1.86-2.27)$ & $3.34(3.10-3.58)$ & 0.0000 \\
\hline SGA (number) & 2 & 3 & 4 & 3 & $0.88^{\star}$ \\
\hline \multicolumn{6}{|l|}{$\begin{array}{l}\text { 5-L-oxoproline }(\mu \mathrm{mol} / \mathrm{mmol} \\
\text { creatinine): }\end{array}$} \\
\hline$<72$ hours & $208^{\star}(161-255)$ & $211^{\star}(157-265)$ & $138(96-180)$ & $105(77-133)$ & 0.0001 \\
\hline Week 1 & $231(161-300)$ & $232(185-280)$ & $182(127-236)$ & $151(102-200)$ & 0.078 \\
\hline Weeks 2-3 & $233(169-297)$ & $211(170-253)$ & $223(145-301)$ & $157(110-204)$ & 0.290 \\
\hline Weeks 4-6 & $263(174-351)$ & $186(136-236)$ & $224(121-327)$ & $170(121-218)$ & 0.204 \\
\hline
\end{tabular}

Infants small for gestational age (SGA) were identified as those with birth weight less than the 3rd centile. Values are mean and $95 \%$ CI. Comparison between groups using analysis of variance. $\mathrm{P}<0.05$, with post-hoc Scheffe's multiple range test: $\star$ compared with $>37$ weeks; $\dagger$ compared with 33-36 weeks; $\ddagger$ compared with $29-32$ weeks. ${ }^{\star \star} \chi^{2}$ test.
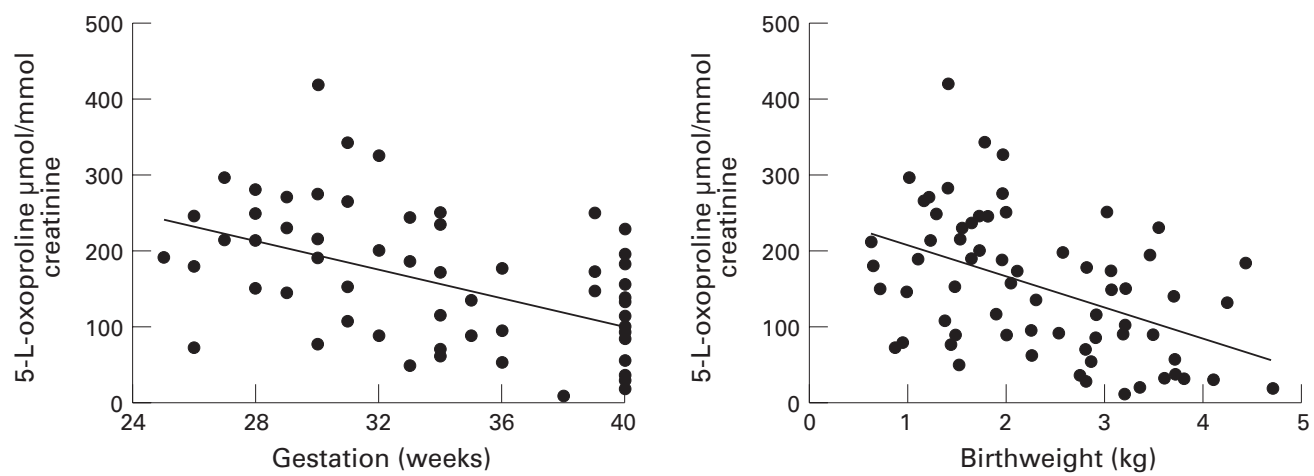

Figure 2 The excretion of 5-L-oxoproline/creatinine was measured in the urine of newborn infants within 72 hours of birth. There was a close correlation between birthweight and gestational age, and both showed a strong correlation with the excretion of 5-L-oxoproline (birthweight $=245-[40 \times 5-L$-oxoproline $] ; r=-0.46, P=0.0001$ : gestational age $=458$ $-[9 \times 5-L$-oxoproline]; $r=0.5, P=0.00002)$.

mmol creatinine, given by gestation, for periods less than 72 hours of postnatal life, 1 week old, 2 to 3 weeks old and 4 to 6 weeks old. If more than one sample of urine was collected from an individual during any time period, the average value was taken to represent excretion of 5-L-oxoproline for that period. For each group of infants and each time period, there was wide interindividual variability, but data approximated a normal distribution in both term and preterm infants, except in term infants at 4 to 6 weeks, where there were two high values. At birth, 5-L-oxoproline:creatinine in urine of infants born before 32 weeks gestation was about twice that of infants born at term, a highly significant difference. For the infants born at 33-36 weeks gestation, urinary 5-L-oxoproline was mid-way between the shorter and the longer gestations, and not significantly different from either.

As expected, there was a close correlation between length of gestation and birthweight, and as they covary it was not surprising that both related to 5-L-oxoproline excretion within the first days of life (fig 2). For each, the correlation was inverse and highly significant (birthweight $=245-[40 \times 5$-L-oxoproline $] ; \mathrm{r}=$ $-0.46, \mathrm{P}=0.0001:$ gestational age $=458-[9$ $\times$ 5-L-oxoproline]; $\mathrm{r}=-0.5, \mathrm{P}=0.00002$ ). The general pattern was for the excretion of 5-L-oxoproline to increase with postnatal age in all groups of infants. For all preterm infants, excretion in the first 72 hours, of 180 $\mu \mathrm{mol} / \mathrm{mmol}$ creatinine, was significantly greater than for term infants-105 $\mu \mathrm{mol} / \mathrm{mmol}$ creatinine-but the difference no longer achieved statistical significance by 6 weeks of age: $225 \mu \mathrm{mol} / \mathrm{mmol}$ creatinine compared with $170 \mu \mathrm{mol} / \mathrm{mmol}$ creatinine, respectively (fig 3 ). For infants born at term, there was no statistical correlation between birthweight and 5-Loxoproline. At all other ages there was no correlation between 5-L-oxoproline excretion and either birthweight or length of gestation. The exclusion of infants identified as small for gestational age did not influence these correlations. At each age 5-L-oxoproline related to excretion at earlier ages. Thus differences in 5-L-oxoproline at birth accounted for most of the variability in excretion at 1 week of age; differences at week 1 accounted for most of the variability at weeks 2 to 3 ; and differences at weeks 2 to 3 accounted for variability at weeks 4 to 6.

The data were explored for other factors which might potentially influence 5-Loxoproline excretion. There was no statistical difference in the excretion of 5-L-oxoproline between those infants who received human milk or formula. As expected, the boys were heavier than the girls for any stage of gestation, but there was no difference in the excretion of 5-L-oxoproline:creatinine by gender. At some, but not all, gestational ages, infants from Nottingham had lower excretions of 5-Loxoproline than those from Southampton. As these differences were not consistent they were ascribed to random variation.

\section{Discussion}

Glycine has generally been considered to be a non-essential amino acid and under normal 


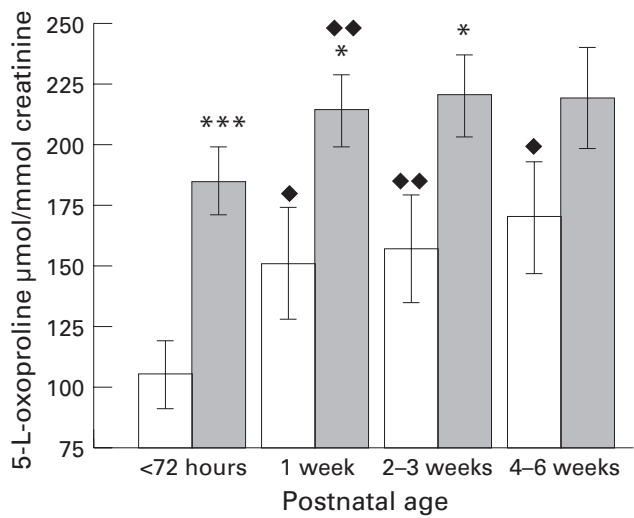

Figure 3 The excretion of 5-L-oxoproline/creatinine was measured in the urine of term infants (open bars) and preterm infants (shaded bars) within 72 hours of birth. and at intervals up to 6 weeks of age. Values shown are mean (SE). with significant differences: ${ }^{\star} P<0.05 ;{ }^{\star \star} P<0.01$ for preterms compared with terms of the same age and ${ }^{\star} P<$ $0.05 ;{ }^{*} P<0.01$ when compared with excretion of 5-L-oxoproline within 72 hours of birth.

circumstances the amount formed in the body is adequate for usual metabolic requirements. ${ }^{7}$ Glycine status could be compromised if either the ability to form glycine were constrained or the demand became relatively excessive. The requirement of a newborn for glycine is high as its availability is linked to every aspect of growth, being consumed directly in the formation of purines and haem, and providing one third of the residues for the formation of collagen and elastin. ${ }^{19}$

It has been estimated that the endogenous formation of glycine is around five to 10 times the dietary intake. ${ }^{719}$ Although the pathways for its formation are not entirely clear, the glycine cleavage system is important. ${ }^{14}$ This pathway requires B vitamins as cofactors, especially folates and vitamin B12, but also riboflavin and pyridoxal. There are only limited reserves of folate at birth, and after birth there is a fall in the serum and red cell concentration of folates which is faster and deeper in premature than full term infants. ${ }^{20-22}$ Clinical deficiency of folic acid is unusual, although hypersegmentation of the neutrophils might be seen more frequently in premature infants. Treatment for two weeks with $20 \mu \mathrm{g}$ folic acid/day does not prevent a low serum folate but $50 \mu \mathrm{g} /$ day is effective. ${ }^{21}{ }^{22}$ Recent evidence suggests that the limited responsiveness to folic acid might be the result of a more severe deficiency of vitamin $\mathrm{B} 12 .{ }^{23} \mathrm{In}$ rats experimental folate deficiency decreases the rate of glycine biosynthesis and the interchange of serine and glycine to about 50 to $60 \%$ of the normal rate. ${ }^{24}$ Whether glycine formation is limited by the availability of folate and B12 in neonates needs to be determined.

The amount of glycine formed in neonates may be insufficient to satisfy needs. ${ }^{12}$ The detoxification and excretion of a number of xenobiotics, such as benzoic acid, is dependent on conjugation with glycine, but in the neonatal period this is constrained with an increase in the excretion of alternative conjugates, such as acetylated compounds ${ }^{12}$ or alanine conjugates. ${ }^{25}$ In infants treated for inborn errors of metabolism which involve urea cycle enzymes, nitrogen excretion is increased by giving sodium benzoate to produce a drain on the glycine pool. The upper dose of benzoate which is tolerable before adverse symptoms develop, about $2 \mathrm{mmol} / \mathrm{kg}$, is associated with an increase in the excretion of 5-oxoproline in urine. ${ }^{425}$

In this study we measured the urinary excretion of 5-L-oxoproline as a marker for glycine status. Neonates excrete five to 10 times the amount of 5-L-oxoproline found in the urine of normal adults, $17 \mu \mathrm{mol} / \mathrm{kg} /$ day. In neonates the excretion of 5-L-oxoproline increased from $105 \mu \mathrm{mol} / \mathrm{mmol}$ creatinine during the first 72 hours after birth, to $160 \mu \mathrm{mol} / \mathrm{mmol}$ creatinine by 2 to 3 weeks of age in normal term infants, and from $180 \mu \mathrm{mol} / \mathrm{mmol}$ creatinine around birth to $225 \mu \mathrm{mol} / \mathrm{mmol}$ creatinine in preterm infants. It remained at this level for some weeks, and in a small number of infants for whom urine samples were available up to 12 to 14 weeks of age, urinary 5-L-oxoproline was $244 \mu \mathrm{mol} / \mathrm{mmol}$ creatinine. Urinary 5-Loxoproline was widely variable among infants at all ages. A part of the variability in the first 72 hours of life was associated with differences in gestational age or birthweight (fig 2). Those infants who excreted higher concentrations of 5-L-oxoproline tended to be high excreters at all subsequent ages. During rapid catchup growth in children recovering from severe malnutrition, excretion of 5-L-oxoproline is 140 to $170 \mu \mathrm{mol} / \mathrm{mmol}$ creatinine and is directly related to the rate of growth. The rate of excretion is reduced following dietary supplementation with glycine, indicating that the raised 5-L-oxoproline is a direct consequence of the demand generated by rapid growth on the available glycine. ${ }^{14}$

Using standard methods of analysis, 5-Loxoproline is difficult to measure quantitatively and therefore is not likely to be identified with any reliability during routine amino acid analysis of urine. It is usual for newborn infants to excrete considerably larger amounts of amino acids in urine than adults and excretion is even higher in preterm infants. ${ }^{26}{ }^{27}$ During the first week of life, the concentrations of many amino acids in urine may be in a similar range to those reported here for 5-L-oxoproline. ${ }^{28}$ However, whereas for most amino acids, losses in urine decrease with age, for 5-L-oxoproline urinary excretion increased as the infants grew older. Increases in urinary 5-oxoproline have been reported under two sets of circumstances. First, 5-D-oxoproline may be found in relatively large amounts in urine, derived either from the diet directly, or as a result of the action of colonic bacteria on D-glutamic acid derived from the diet. ${ }^{62}$ The 5-L-oxoproline formed as a normal metabolic intermediate in the body, is readily acted on by the enzyme 5-Loxoprolinase with the formation of glutamic acid, and is only present in urine in small amounts, compared with 5-D-oxoproline. ${ }^{630}$ The second situation of increased urinary excretion is in inborn errors of metabolism involving enzymes of the $\gamma$-glutamyl cycle: defects of either glutathione synthetase or 5-L-oxoprolinase, ${ }^{6}$ when excretions in the 
region of 9 to $25 \mathrm{mmol} /$ day are found, compared with $21 \mu \mathrm{mol} /$ day in normal infants in the present study.

The finding that the excretion of 5-Loxoproline is higher in the newborn period than at other ages implies that the requirement for large amounts of glycine for normal growth and development is not being satisfied. For the preterm infant the mismatch is even greater. It may be that the normal pathways for the formation have not adequately matured, or that there is a relative deficiency in the cofactors required for its synthesis, compared with the unusually high demand. It seems likely that both possibilities contribute, to differing degrees, depending on the circumstance. The consistent difference between term and preterm infants in urinary 5-L-oxoproline implies an immaturity of pathways. Whatever the cause, it can be presumed that when the excretion of 5-L-oxoproline is increased, one or other metabolic function is not being adequately satisfied. The compromise might be shared among collagen formation and bone growth, haem formation, bile salt formation with implications for lipid digestion, or the ability to maintain the cellular glutathione status and hence cellular function and integrity.

The extent to which the availability of glycine might be increased, either by dietary supplementation with cofactors, with glycine itself, or its precursors needs to be assessed. In inborn errors of urea metabolism, when treatment with large doses of sodium benzoate induces a persistent added drain on the availability of glycine, direct supplementation with glycine would increase the nitrogen intake and defeat the purpose. However, supplementation with the precursors of the carbon chain from which glycine is formed, such as pyridoxylate, could enhance the removal of nitrogen without simultaneously compromising glycine status. The possibility of a poor folate or B12 status in newborn and preterm infants suggests that determining the extent to which the excretion of 5-L-oxoproline might provide a sensitive measure of the adequacy of supplementation with either vitamin. There may be concern about giving supplemental glycine itself, as there have been reports of possible toxic effects when the amino acid was added in generous amounts to total parenteral nutrition solutions as a "nitrogen filler." ${ }^{31}$ However, the problem appears to have been overstated; it is more likely that a deficiency of arginine compromises the function of the urea cycle. ${ }^{32}$ Most glycine metabolism is controlled by the liver, and is directly linked to other aspects of intermediary metabolism. In the short term, limited availability of glycine could be buffered by a reduction in its flow to high demand pathways, such as the formation of haem or creatine formation. Over longer periods, limiting the flow to collagen which could translate to a constraint on linear growth, might be more efficient use of resources. The metabolic handling of many drugs consumes glycine, thereby straining the system further. Func- tional glycine deficiency should be regarded as a possible side effect of therapeutic interventions.

This work was carried out with support from the Nestle Nutrition Research Grant Programme.

1 Jackson AA, Shaw JCL, Barber A, Golden MHN. Nitrogen metabolism in preterm infants fed human donor breast milk: the possible essentiality of glycine. Pediatr Res 1981;15:1454-61.

2 Catzeflis C, Shultz Y, Micheli JL, Welsch C, Arnaud M, Jequier E. Whole body protein synthesis and energy expenditure in very low birthweight infants. Pediatr Res 1985;19:679-87. 3 Snyderman SE, Boyer A, Roitman E, Holy LE, Prose PH. growth. F Nutr 1962;78:57-63.

4 Jackson AA, Badaloo AV, Forrester T, Hibbert JM, Persaud C. Urinary excretion of 5-oxoproline (pyroglutamic aciduria) as an index of glycine insufficiency in normal aciduria) as an index of glycine
man. Br f Nutr 1987;58:207-14.

5 Jackson AA, Persaud C, Meakins TS, Bundy R. Urinary Jackson AA, Persaud C, Meakins TS, Bundy R. Urinary
5-L-oxoproline (pyroglutamic acid) excretion in normal 5 -L-oxoproline (pyroglutamic acid) excretion in normal
adults increases on vegetarian or low protein diets. $\mathcal{F}$ Nutr 1996;126:2813-22.

6 van der Werf P, Meister A. The metabolic formation and utilization of 5-oxo-L-proline (L-pyroglutamate, L-pyrrolidone carboxylate). In: Meister A, ed. Advances in Enzymology. New York: John Wiley and Sons, 1975;51966.

7 Jackson AA. The glycine story. Eur f Clin Nutr 1991;45:59-

8 Widdowson EM, Southgate DAT, Hey EM. Body composition of the fetus and infant. In: Visser HAK, ed. Nutrition and Metabolism of the Fetus and Infant. The Hague: Martinus Nijhoff, 1979:169-77.

9 Christensen HN. Amino acid nutrition across the placenta. Nutr Rev 1992;50:13-24.

10 Poley JR, Dower JC, Owen CA, Sticker GB. Bile acids in infants and children. $\mathcal{F}$ Lab Clin Med 1976;63:83-8.

11 Javenpaa AL, Rassin DK, Kuitunen P, Gaull GE, Raiha NCR. Feeding the low birth weight infant. Diet influences bile acid metabolism. Pediatrics 1983;72:677-83.

12 Vest MF, Rossiter R. Detoxification in the newborn: the ability of the newborn infant to form conjugates with glucuronic acid, glycine, acetate and glutathione. Ann N Y Acad Sci 1963;111:183-98.

13 Thompson JA, Miles BS, Fennessay PV. Urinary organic acids quantitated by age group in a healthy paediatric population. Clin Chem 1977;23:1734-8.

14 Persaud C, Forrester T, Jackson AA. Urinary excretion of 5-L-oxoproline in severe childhood malnutrition and the 5-L-oxoproline in severe childhood malnutrition and the 30 .

15 van der Werf P, Stephani R, Meister A. Accumulation of 5-oxoproline in mouse tissue after inhibition of 5-oxoprolinase and administration of amino acids: evidence for function of the $\tau$-glutamyl cycle. Proc Natl Acad Sci USA 1974;71:1026-9.

16 McPherson HT, Slater JS. $\gamma$-amino-n-butyric, aspartic, glutamic and pyrrolidone carboxylic acid, and their determination and occurrence in grass conservation. Biochem $\mathcal{f}$ 1959;71:654-60.

17 Lund P. UV-method with glutaminase and glutamate dehydrogenase. In: Bergmeyer HU, ed. Vol VII. Metabolites 3. Lipids, amino acids and related compounds. Oxford: Oxford Lipids, amino acids and related com
University Press, 1984:357-63.

18 Bonsnes RW, Taussky HH. On the colorimetric determination of creatinine by Jaffe's reaction. $\mathcal{F}$ Biol Chem 1945;158:581-4.

19 Neuberger A. The metabolism of glycine and serine. Comp Biochem 1981;19A:257-303.

20 Roberts PM, Arrowsmith DE, Rau SM, Monk-Jones ME. Folate status in premature infants. Arch Dis Child 1969;44:637-42.

21 Hoffbrand AV. Folate deficiency in premature infants. Arch Dis Child 1970;45:441-7.

22 Shojania AM. Folic acid and vitamin $B_{12}$ deficiency in pregnancy and the neonatal period. Clin Perinatol 1984;1:43359.

23 Worthington-White DA, Behnke M, Gross S. Premature infants require folate and vitamin B-12 to reduce the severity of the anemia of prematurity. Am $f$ Clin Nutr 1994;60:930-5.

24 Arnstein HRV, Stankovic V. The effect of certain vitamin deficiencies on glycine biosynthesis. Biochem $f$ 1956;62:190-8.

25 Shinka T, Inoue Y, Kuhara T, Matsumoto M, Matsumoto I. Benzoylalanine: detection and identification of an alanine conjugate with benzoic acid in hyperammonemic patients treated with sodium benzoate. Clin Chim Acta 1985; 151:293-300.

26 Dustin EMW, Moore S, Bigwood EG. Chromatographic studies of amino acids in early infancy. Metabolism 1953;4:75.

27 Gil A, Periago JI, Faus MJ, Martinez A, Sanchez-Medina E, Molina JA. Plasma and urine amino acids in term infants fed human milk and formula. F Clin Gastroenterol 1987;2:155-61. 
28 Woolf LI, Norman AP. The urinary excretion of amino acids and sugars in early infancy. F Pediatr 1967;50:271-95.

29 Oberholzer VG, Wood CBS, Palmer T, Harrison BM. Increased pyroglutamic acid levels in patients on artificial diets. Clin Chem 1975;62:299-304

30 Qureshi IA, Clermont P, Letarte J. The importance of glyoxylate and other glycine precursors in the hepatic and renal conjugation of benzoate in normal and hyperammonemic mice. Can f Physiol Pharmacol 1989;67:1426-30.
31 Stegnik LD, Bell EF, Daabees TT, Andersen DW, Zike WL, Filer LJ. Factors influencing utilization of glycine, glutamate and aspartate in clinical products. In. Blackburn GL, Grant JP, Young VR, eds. Amino Acids: Metabolism and Medical Applications. Boston: John Wright, 1983;123-46. 32 Winters RW, Heird WC, Dell RB. Parenteral amino acid nutrition in infants. In: Blackburn GL, Grant JP, Young VR, eds. Amino Acids: Metabolism and Medical Applications. Boston: John Wright, 1983;327-32.

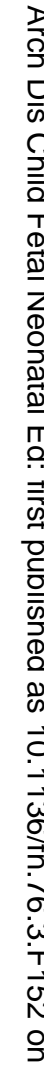

